\section{LA CULTURA DE LA IMAGEN Y EL DECLIVE DE LA LECTO-ESCRITURA}

\author{
Fernando R. de la Flor \\ Universidad de Salamanca \\ C/ San Pablo 26-28 $5 \mathrm{E}$ \\ 37001 Salamanca \\ frflor@usal.es
}

\begin{abstract}
This article surveys the so-called visual turn that has currently taken place in cultural studies. It departs from the existing rivalry between writing and image and it advances a genealogy for this confrontation. This study insists on the diverse effects that the so-called visual turn has brought about in the reorganization of various areas of academic studies.
\end{abstract}

KEY WORDS: Visual turn.

\section{THE CULTURE OF IMAGES AND THE DECLINE OF TEXT-BASED WRITING}

RESUMEN: El artículo aborda en perspectiva el llamado visual turn producido en los estudios culturales: remonta la cuestión de una rivalidad entre la escritura y la imagen, estableciendo una cierta genealogía para este "enfrentamiento". Para concluir, el trabajo finalmente recala en ciertos efectos que dicho giro visual tendrá sin duda en la reorganización de los campos de saber académicos.

PALABRAS CLAVE: Giro visual.

Quien no ama la imagen es injusto con la verdad Filóstrato

El parangón entre las artes del discurso textual y aquellas otras que crean las formas bi o tridimensionales es un paso dialéctico clásico fuertemente enraizado, al menos desde la cultura humanistica en lo que fue su primer periodo', y ello alcanza todo tipo de reformulaciones en todas las estéticas epocales, en las que ciertamente se ha discutido con qué pertenencia uno y otro de aquellos sistemas de representación "representan" verdaderamente mejor el mundo ${ }^{2}$, satisfaciendo el horizonte de perspectivas que las sociedades históricamente depositan en estos procesos.

Si bien es verdad que se ha primado en muchas circunstancias aquel pensamiento de Horacio que, haciendo reposar toda su confianza en la escritura de sus Odas, llegó a decir de ellas que, sin duda, por estar escritas y ser reproducibles serian más duraderas que los propios monumentos conmemorativos de bronce que ponían ante los ojos la evidencia de una memoria única, solidificada y real ("Exegi monumentum aere perennius"... "construiré un monumento más duradero que el bronce"), es evidente que los tejidos

mitopoéticos que piensan en la profundidad y verdad de la representación le han concedido de siempre al mundo de las formas y de las figurae una suerte de monarquía en lo que es el régimen de la mimesis de ese mismo rea $\beta$, y ello con una potencialidad y registro más amplio del que pudiera alcanzarse a través de la escritura.

Después de un lapsus temporal de acaso quinientos años -el que corresponde al primado de la imprenta-, acaso estemos reingresando de nuevo en una suerte de "civilización de la imagen", que destronaría de su lugar a la cultura basada en la escritura. La potencia de la imagen; el triunfo indiscutible de la imagen y su correspondiente ubicuidad en la vida de la polys contemporánea sería el corolario de este nuevo estadio ${ }^{4}$. Potencialidad ésta a la que no puede, ciertamente, aspirar la palabra escrita, en razón sobre todo del cambio necesario de código sígnico (que en la escritura ya no es morfológicamente analógico al relieve y superficie del mundo, como, al cabo, sí lo puede ser el trazo o el modelado picto-escultórico ${ }^{5}$ y, también, 
por la abierta abstractalización que tales signos alfabéticos comprometen $^{6}$; es decir: su ser completamente arbitrario (al menos en la escritura occidental). Una última cuestión será la del propio ritmo secuencial de la lectura de signos tipográficos, la cual, realizada en un orden sucesivo, pierde entonces ventaja frente a la simultaneidad estructural y orgánica que alcanza la visión de imágenes.

Si de simulacros se trata, la imago mentis, generada por las escrituras en su lector (cuando lo encuentran ${ }^{7}$ ), no puede al cabo competir con la imago vera que producen las artes miméticas por excelencia: la pintura y la escultura (seguidas por la ficción de realidad que aporta en nuestros días el píxel; y, antes, la propia imagen sin soporte, la imagen proyectada) ${ }^{8}$. En definitiva, el poder de una activa "persuasión" y de una apelación contundente a la imaginación humana se encuentra profundamente enraizado en las configuraciones formales y plásticas de las imágenes -imago; figura-, cuya fuerza turbulenta y acaso inconsciente ${ }^{9}$ ha sido históricamente más relevante y decisiva que las del propio texto (Moxey, 2003), y de cuya compleja fenomenología y perceptualismo -además del "efecto pragmático" que encadena su propia presencia- empezamos a tener una información más detallada, sobre todo por la antropología, ciencia que nos ha revelado la trascendencia mayúscula de la imagen en lo que fue la constitución de la humanidad arcaica (Brysson, 1991). En definitiva: "La imagen es una cuestión vital, viva y altamente compleja: un verdadero centro neurálgico, la clavija dialéctica por excelencia de la vida histórica" (Didi-Huberman, 2005, 55). Las imágenes mueven con más fuerza que los textos, ésta podría ser la conclusión, la de que la fuerza pragmática está siempre del lado de la imagen; que su presencia enlaza y desemboca en lo vital de modo más natural que lo puede hacer el texto. $Y$, entonces, en ese caso, la imagen, por encima de la abstractalización que supone la escritura, promueve un efecto de "real" cuya reconquista ha podido constituir, por otra parte, un horizonte de nuestra posmodernidad (Foster, 2001).

En definitiva, el texto, si bien es capaz de desarrollar un mundo propio, no parece en suma tan capaz de venir a desembocar en lo real, apareciendo como más propio de él el reino de lo imaginario y de lo radical virtual ${ }^{10}$.

Esta supremacía de la imagen en cuanto simulacro y "analogon" de lo real, que a menudo se ha jugado en el terri- torio de lo mítico -tal y como queda representado en la historia de Pygmalion ${ }^{11}$-, y que, en todo caso, tiene su raíz en unas estructuras antropológicas compartidas por toda la humanidad y con base en el reservorio psíquico colectivo al que no por nada denominamos "imaginario"12, ha sido, sin embargo, continuamente negada por los teóricos de una cultura unilineal, los cuales han querido suponer siempre que la escritura adviene en estadios superiores de la cultura, y que la misma releva completamente con su autoridad manifiesta y dogmática los restos "primitivos" y "animistas" depositados en la cultura visual, en la imagen ${ }^{13}$.

Quizá lo más significativo de las percepciones a que nos conduce nuestro tiempo es la de que con toda evidencia se estaría produciendo una nueva y más potente (acaso también decisiva, por última) translación de una visión del mundo generada a través de textos ${ }^{14}$, a otra basada en la visión del mundo en cuanto imagen, o reducida a imagen, recordando tal vez aquí la pulsación efímera de la misma, la inestabilidad temporal de la que se habría hecho ya eco un San Pablo: Pertranseat imago mundi.... "pasará la imagen del mundo...". En efecto, la antigua metáfora del "libro del universo", que pudo ser incluso teóricamente desarrollada por ingenios peninsulares como Alejo Venegas, ha sido definitivamente transformada en "imago mundi" (Venegas, 1540). Focalidad, entonces, de lo visual; capacidad de la imagen por contener, por dar cuenta del mundo ${ }^{15}$, y, subsidiariamente, y como corolario, quizá comencemos a situarnos sobre la pista de un pensamiento imaginativo, mucho más adelantado que un pensamiento conceptual, desequilibrándose a favor de lo primero el viejo orden histórico, en el cual se compensaba, por un lado, el poder de la concepción y, por otro, el de la representación. La vida psíquica se desenvuelve en el terreno de lo imaginario, en todo caso estamos habitados por representaciones mentales de imágenes (Sartre, 2005).

Los ídolos de la tribu en estos momentos históricos son, antes que nada, eso, eidolon, imágenes, y deberemos recordar a este respecto que en el relato fundador bíblico Moisés rompe las tablas de la Ley evidenciando, en un gesto de la máxima relevancia simbólica, la superior capacidad persuasiva que sobre el pueblo judío tenían en ese momento los simulacros (sacrílegos) (Ginzburg, 2000) a los que adoran por estar dotados de una fuerza apotropaica, por un investimiento que da cuenta con vigor inusitado del 
anudamiento simbólico allí producido y canalizado en el icono, y, por tanto, casi se diría que encarnado o apresado en un objeto que posee dimensiones y existencia física, y cuya virtud última es la de trabar una relación empática con su observador, constituyéndose en una suerte de imagen sublime y cultual $^{16}$. Las formas plásticas cuajan en universales antropológicos, directamente reconocibles y de una gran potencialidad expresiva. Abby Warburg, que partió desde principios del siglo XX a la búsqueda de estas imágenes radicalmente habitadas de una poderosa energía semántica, las denominó: pathosformel y por ellas podemos entender:

"Un conglomerado de formas representativas y significantes, históricamente determinado en el momento de su primera síntesis, que refuerza la comprensión del sentido de lo representado mediante la inducción de un campo afectivo donde se desenvuelven las emociones precisas y bipolares que una cultura subraya como experiencia básica de la vida social" (Burucúa, 2006, 15).

Una elaboración más sofisticada de esta idea de arquetipos figurales es la teorización de Walter Benjamín de la "imagen dialéctica", definida por el filósofo como aquello que "despierta" e induce un conocimiento fulgurante mediante el cual "el Otrora se encuentra con el Ahora". Esta figura, que es en sí misma dialéctica, no es de otra naturaleza que no sea "figurativa"17.

De este modo resulta que Pigmalión, a través de la creación de una imagen pregnante y casi viva, siempre se enfrentará con ventaja a Kadmos (este último el organizador mítico del mundo de la escritura), y el relato del primero alcanzará así más fuerza definitoria y más entidad y presencia en la cultura ${ }^{18}$, en la medida misma en que la historia del hombre, que logra dar vida a una representación que él mismo crea, funda la institución del arte de la fabricación de imágenes, como convocación absoluta de lo que siempre permanece ausente en la propia representación: la vida. Y entonces, cabe decir de esta vida que es más susceptible de ser evocada y conjurada a mostrarse encarnándose en la materia que en la propia sustancia lingüística ${ }^{19}$.

Así, la creación plástica (estariamos tentados de decir "alfarera") del analogon naturalista (amparada en las cosmologías primitivas, en el inconsciente y en los mitos) aspira sin ambages a convertir en presencia lo que siempre se manifiesta como ausencia, reintegrando el "arte" en la vida (dando soplo vital a las formas, a las figuras) y borrando por este procedimiento (que contiene dosis importantes de engaño, de tromp-l-oeil) las barreras entre ambos. Esta historia pues de Pygmalion, como dicho fundador que es, devuelve al hombre su anhelada posición demiúrgica, y hace reposar sobre las imágenes una posibilidad que nunca alcanzarán los propios textos, en este sentido, sólo manifestaciones de la capacidad reduplicativa del hombre (en cuanto actúa exclusivamente en una suerte de segunda naturaleza que ocupa un dominio mental, fantasioso).

Sucede pues que los Zeuxis y los Apeles han devenido al cabo como aquellas figuras centrales en el desarrollo de la representación en la cultura occidental, y ello incluso más que lo puedan ser aquellos otros Zeuz (el dios inventor de los caracteres de la escritura) o Zamus (el monarca al que le fue regalado el alfabeto escrito), citados por Platón (Fedro), que pusieron entre los hombres un pharmakon que había de devenir peligroso y ambiguo: la escritura (Derrida, 1975), precisamente por atenuarse en su uso la resonancia originaria del mundo y promover en consecuencia un "olvido" del mismo o, al menos, de la experiencia sensorial del mismo. Víctor Hugo viene aquí al caso cuando prevé la muerte del monumento "asesinado" (la expresión es de un más tardío Marcel Proust) por la imprenta, que difunde de él discursos que no están ya sujetos a experiencia directa (Hugo, 2006).

\section{Ofensiva visual}

Este antiguo enfrentamiento entre sistemas de representación sobre el que han sido vertidos ríos de tinta alcanza hoy, entre nosotros, un momento verdaderamente climático y especial. Esto es así porque parece que la "civilización de la imagen", y, en general, el proceso que ha podido ser conocido como "imagocentrismo" (o, también, si lo que se acentúa es la otra polaridad del hecho visual: el "ocularcentrismo") avanza sobre sí mismo, descubriendo las fronteras insospechadas de lo digital, lo holográfico, lo virtual $^{20}$, generando así una "democracia" visual (y la correspondiente "imagen democrática"), al cabo una verdadera internacional de la imagen total (del, diríamos, efecto "pantalla total"21), en sí mismo todo ello más potente y universalizador que lo logrado por la civilización del texto 
a partir de la difusión de la imprenta; lo que ha generado que, en realidad, de modo masivo, la era de la reproductibilidad técnica de la imagen ( $y$, en particular, de la imagen de la obra de arte ${ }^{22}$ ) haya venido a suceder -e incluso a dejar en la sombra- aquella primitiva reproductibilidad técnica que para siempre vincularemos a una cultura del impreso y del texto (aunque lo fuera también, al cabo, de la propia imagen -lving, 1953-), cultura tipográfica forzadamente en ello reductora, y pronto ya dispuesta para ser considerada naif, arcaica, rudimentaria.

Podemos incluso suponer con Latour (1998), que a la imprenta basada en la tipografía como objeto fetiche único del racionalismo moderno, le envuelve ya hoy otro fenómeno superior, el cual atañe a la completa remodelación de la visión y al alumbramiento de la perspectiva también moderna que permite unos traslados cada vez más perfectos en sus efectos realistas del mundo no ya ahora "sobre el papel" (Olson, 1997), sino sobre las superficies inmateriales, sobre el aire mismo, como sucede en el caso notable del holograma. En definitiva, nos encontramos en el último y más potente de los regímenes de visualización que ha conocido la modernidad (Jay, 2003).

El ataque sobre lo textual, el cual proviene del mismo engrandecimiento de la dimensión que cobra la esfera de lo visual, hace que el sentimiento de la lengua se repliegue hacia realizaciones altamente sofisticadas donde encuentra una suerte de última línea de resistencia. En palabras de Jordi lbáñez, se produce la "exacerbación de la función poética convertida en reserva testimonial" (Ibáñez, 2004).

Diremos que, entre tanto, en realidad lo que ha sucedido es un cambio de escenario trascendental, pues el lugar de diafanía de la imagen es hoy, no el sancta sanctorum de la reserva intelectual del gabinete, del estudio, del circuito de las letras constituidas como tales, sino la extensión inabarcable de la vida cotidiana en donde campea sin restricciones la imagen multiplicada y el simulacro general que afecta a todas las almas de la polys.

La visión, en suma: la "lógica de la mirada" (Brysson, 1991), como quieren los modernos promotores de una cultura o civilización de la imagen, tiene las mismas (si no superiores) cualidades hermenéuticas que el propio lenguaje, construye al cabo mundo, y tal vez lo hace de un modo más firme e impresivo de aquello a que alcancen a movilizar los textos (cuyas praxis, en todo caso, siempre supone o requiere un apartamiento, una distancia, una diferencia, una reserva, una retirada del mundo en derredor ${ }^{23}$ ). Cuando de estos últimos, los textos, se trata, el acceso al campo del escrito se encontrará siempre custodiado por unos protocolos insoslayables, los cuales aumentan fantásticamente en el caso de la alta cultura escrita. Mientras, la "lectura" de la imagen es siempre algo inmediato, se ofrece desregularizado, e, incluso, está dotado de un aspecto inquisitivo, interrogativo, que demanda una aproximación primera al sentido de la misma y que en sí mismo lo fuerza, haciendo que la percepción de la imagen contenga ya inevitablemente los primeros pasos de lo que es su propia interpretación ${ }^{24}$.

La imagen convoca de modo instantáneo un sentido que se manifiesta en un aspecto empático y profundo, haciendo que la respuesta a la figuración desencadene una mecánica psicológica en la que alcanzan todo su papel, como escribe Freedberg, sentimientos tales como la admiración, el sobrecogimiento, el terror, el deseo... (Freedberg, 1989), que es lo que constituye especificamente el "visual thinking" (Arnheim, 1969). Los analfabetos "técnicos", que sí existen en el dominio lecto-escritor, no tienen homólogos en el espacio de la imagen, donde, en efecto, en rigor no los hay, ya que, en todo caso, aquélla siempre alcanza una suerte de cognoscibilidad y transmite una cierta información a aquel sujeto ante el que se constituye, podriamos decir que estructurándole también y constituyéndole a su $v e z^{25}$. Con toda evidencia, hoy comenzamos a ver alzarse una "cultura visual" 26 , que en su objeto y en sus métodos parece inflexionar de modo tan potente, al menos (pero en realidad se revelará como mucho más) como la antigua cultura basada en el discurso, en el texto, en el escrito ${ }^{27}$. En definitiva, está en marcha una revolución epistémica y un cambio en lo que es el paradigma cognitivo ${ }^{28}$.

Ello da pie a formular ya una suerte de ley del giro visual, y a interpretar los signos acentuados de la decadencia palpable del escrito, y ello en un aspecto que nos es específicamente cercano: el de la constitución de un campo de estudios humanísticos propio, es decir: formado en la plena posmodernidad.

Es una evidencia el hecho de que tal emergencia de lo visible (por encima de lo legible), tal ubicuidad de la imago, como veremos, obliga a una reconstrucción entera del 
campo de saberes humanísticos, en cuyo centro siempre tuvieron un lugar de privilegio las disciplinas de la palabra (sacralizadas en la forma del codex), manifestándose tradicionalmente de manera ancilar aquellas otras que se ocupaban de la imagen ${ }^{29}$. De lo que tal vez constituyan un ejemplo los propios libros de aquellos dos Filóstrato, el Joven y el Viejo, Imagénes (Eikones), en donde, de un modo explícito, se señalaba la vocación instrumental de la imagen a través del relato del segundo sobre el modo en que en la Nápoles helenística, huyendo de pronunciar los discursos en el foro, se inventan las galerias de imágenes para formar en la palabra a sus generaciones de jóvenes, quienes necesitarán de este "suplemento" imaginal para asimilar las abstrusas lecciones de la política y de la filosofía $^{30}$. La cuestión aquí permanece incólume: ¿quién es el suplemento de quién en esta historia fundacional de la lectura comentada de imágenes? 0, dicho ahora en términos debatidos por Derrida (Derrida, 1976), cuál actúa aquí de parergón: ¿es la imagen lo que está fuera del texto a modo de un marco, de un contexto; o es más bien el propio texto el que ilustra y acota la imagen ? $^{31}$. Quizá no haya necesidad de remontarse tan lejos en la resolución de esta quaestio, pues, al cabo, todo ha dado en que es, en efecto, la organización misma del capitalismo tardío en torno a la imagen espectacular ${ }^{32}$, la que fuerza inevitablemente esta ascensión de la cultura de la imagen, ahora ya en la forma totalizadora de una ciber-óptica, que releva a su vez de su posición, tanto a las realizaciones figurativas de órdenes imaginarios que la preceden, como, en otra perspectiva, a aquella superior manifestación de "legibilidad" alcanzada por formas como la novela o el periodismo escrito en el siglo XIX, hasta hace poco tenidas como los medios de mayor alcance y difusión de toda la historia y los instrumentos cumbre en la creación de una lectura de mundo.

En efecto, la imagen releva a la escritura, pero también la relega a constituir su comentario, a ilustrarla; la fuerza a una servidumbre, disponiéndola en una posición ancilar, dado que la imagen reclama ahora ser, por encima del texto, "el instrumento de análisis del mundo y el mejor soporte de la memoria [histórica]" (Choay, 2007, 83).

Nuestro tiempo, indudablemente, se hace más legible en lo imaginal y visivo, que en la postulación que del mismo puedan hacer las escrituras (o sus correlatos orales, pues también cabe decir que ha retrocedido la posición del oído como canal hermenéutico, antaño privilegiado). En efecto, entretanto puede que se haya hecho verdad el que "la vida moderna" -como ha escrito recientemente un especialista de la cultura visual- "se desarrolla ya toda ella en la pantalla" (Mirzoeff, 2003, 17), y, en todo caso, metodológicamente se aventura ahora una vía de privilegio en el acceso a la dimensión histórica de lo humano, siendo este acceso del orden de lo visual; se realiza a través de objetos visivos. Si nos preguntamos por la genealogía de esta supremacía de la imagen adquirida por encima del poder de los discursos y del objeto escrito, diremos que fue el propio Benjamín quien puso esa misma imagen en el centro de la vida histórica; asunto que fue materia en su día del gran libro de Peter Burke, Visto y no visto (Burke, 2001).

En todo caso, la ubicuidad de las imágenes, su actual omnipresencia espectralizada (condición que se da en el caso de la reciente expansión de las llamadas "imágenes incorpóreas") en el campo de la óptica social, donde han terminado por formalizar una "cultura de la pantalla", con su inmanencia logra definitivamente desplazar de su centro de gravedad ponderada a las culturas del escrito, antaño las poderosas y realmente significativas en el campo de la historia cultural. Lo que, como corolario, tiene otro efecto, que es por ahora el que nos interesa en adelante analizar aquí. Pues, en realidad, lo que ha venido a suceder en el espacio académico de las Humanidades, puesto radicalmente en crisis por esta revolución epistémica, es que hoy el campo de la antigua batalla se ha desplazado desde las competencias y pugnas de las prácticas simbólico-plásticas, por un lado, y las simbólicodiscursivas y textuales (por otro) a lo que es el terreno especulativo hermenéutico y crítico de las propias disciplinas que las soportan y las teorizan, abriendo una cierta fosa entre las mismas, y enfrentando duramente ambas formaciones por la hegemonía en el dominio del campo simbólico de la cultura.

Cuestión esta a la que nos dedicaremos en lo que sigue, según promesa contenida en el exergo y título de este comentario.

\section{RUPTURA DEL ANTIGUO ORDEN DISCIPLINAR}

La lógica del capitalismo tardío o avanzado termina por imponerse en el espacio social con una firmeza que arre- 
bata a las formaciones sobrevivientes y a los órdenes simbólicos arcaicos todo su fundamento de $\operatorname{ser}^{33}$. Los debates cerrados, los consumos restringidos, las interpretaciones esotéricas son devueltos hoy a su matriz decisiva (y acaso última, pues integra ya al total de lo social): se trata de la esfera pública, convertida en el lugar y en el hogar del tránsito de las cosas. Allí, en el interior de esa esfera de lo público, lo que se produce es el consenso sobre el consumo que las cosas deben tener. Es ese el lugar último y tribunal postrero de la negociación, escena de la atribución y el espacio natural que toda producción simbólica se da a sí mismo en tanto instancia decisiva e instancia de superior decisión.

Una actual estetización general, masiva y democrática, de las imágenes del mundo habría pues aniquilado el sentido de un arte superior o elevado, y dado por concluida la relación privilegiada de éste con la "verdad" 34 , mientras que la propia cuestión de lo "bello", y acaso también la de lo sublime, se vuelve irrelevante, abriendo de este modo el paso a una más general y potente epistemología del ver o de la construcción social de la visión (Virilio, 1989), que tiene su momento historicista en la formación de saber que se ocupará de la "arqueología de la mirada". Tal desinvestimiento simbólico y, en realidad, fin de régimen para el arte elevado habría venido siendo anunciado por las mismas vanguardias que, en el caso de la música, preconizaban ya la llegada imparable de una "música de mobiliario", cuya presencia sería en el futuro comparable a la de la manifestación del papel pintado en la pared. Podríamos decir, en efecto, con Arthur Honegger:

Nuestras artes se van, se alejan... temo que la música sea la primera en desaparecer. Cuanto más miro a mi alrededor, más la veo desviarse de su vocación: la magia, el encantamiento, esa solemnidad que debe envolver la manifestación artística (Fernández Magdalena, 2005, 37).

En todo caso, ciertamente a lo que asistimos en este momento en el debate crítico es, precisamente, a la presentación y puesta en escena de esa "muerte del arte"; momento en el que, cumplida su misión, e, incluso rebasadas ya sus últimas emergencias históricas en tanto que praxis revolucionaria y radicalización de la teoría crítica, el arte se habría disuelto sin fronteras en la corriente de la vida, y ya no constituiría más esa especial posición desde la cual se hacía posible la toma de autoconsciencia ${ }^{35}$.
La posición singular, solitaria, elevada que el arte hasta este momento habría tenido es, en efecto, como habria avisado Hegel, ya "cosa de otros tiempos". Fenómenos entonces concomitantes, por un lado, éste de la muerte 0 fin del arte con la agresiva afirmación de un campo de estudio que mediante un acto imperialista y arriesgado convierte automáticamente en objeto de la disciplina toda la producción social de la imagen. La formación académica resultante -a la que provisionalmente bien podemos denominar: Estudios de Cultura de la Imagen-, en consecuencia, amenaza ya, desde su foco originario en la universidad americana, en convertirse en la nueva estrella rutilante en el cielo de los estudios de Humanidades. No se trata, en todo caso, de una operación de partogénesis, sino de un movimiento a partir del cual un campo de estudio crece y engloba la unidad inferior de la que partía. Podemos decir así que la historia del arte, núcleo originario en los últimos doscientos años de una historia del objeto artístico (que subsidiariamente se enfrentaba a una homóloga historia de la literatura/filología, la cual realizaba su praxis sobre un canon de textos), ha sido definitivamente englobada en una superior unidad, que en cierto modo la anula, o, en todo caso, la desplaza: de nuevo, los estudios de cultura de la imagen, los estudios visuales que se dan por objeto, la cultura visual generada sin recortes en lo social. En realidad, la cultura visual no sería otra cosa sino el precipitado, la consecuencia misma del "encuentro" -como escribe Mirzoeff- "de la modernidad con la vida cotidiana" (Mirzoeff, 2003, 101).

Frente a esta unidad superior, en realidad, la historia de las artes plásticas no constituyen sino una "provincia", una parte necesariamente integrada en el conjunto superior. Estos estudios parten, pues, de un reconocimiento expreso: el de que al presente resulta imposible separar los objetos visuales artísticos de otro tipo de imágenes o realizaciones; faltos de criterio de discriminación en un universo de dobles y simulacros, la formación científica parece haberse así rendido a la evidencia y comenzado a desarticular el viejo paradigma disciplinario sobre el que estaba montada toda su misión ${ }^{36}$.

En efecto, el nuevo estudio de la imagen, sin más especificaciones ni fronteras en su interior, se reorganiza ahora diciéndole adiós a la hasta hoy todopoderosa metodología historicista en que ha abundado su análisis. En lugar de ello -de ese corte diacrónico que siempre impone el mo- 
delo académico, como reflejo de su voluntad de hacer historia- la imagen se reintegra en el campo antropológico, donde se revela su pura sincronía, su inmediatez funcional, su conexión directa con los "hechos de vida". Cabe decir aquí, como apostilla, que el trabajo desrealizador de la esfera del arte autónomo que llevó a cabo Marcel Duchamp tiene mucho que ver con la situación actual que tratamos de describir, en la que un objeto privilegiado y la formación científica que lo ha legitimado en la historia inician su retroceso, mientras ceden definitivamente el interés social, desplazándose a otras prácticas más abiertas y omnicomprensivas para con lo que es la nueva situación creada. En todo caso, apuntemos a aquel Marcel Duchamp como un verdadero desarticulador de un régimen restrictivo de la imagen, asi como un artista que se constituye en ejemplo para un porvenir inmediato del que se convierte en su máximo profeta. Martín Jay ha sustantivado el registro de operaciones deconstructivas en que se inscribe el ciclo de trabajo conceptual de Marcel Duchamp. En efecto, el artista francés (el más influyente en el panorama artístico de nuestro tiempo) abre el camino del desinterés por "lo estético", que ya no se ofrece más como objeto de una búsqueda y que conllevaba el discurso del canon, hoy combatido y pulverizado. Duchamp -los "duchampianos" de toda hora-, pues, desafía la institución diferenciada del arte, y se salen y sacan también sus producciones del campo artístico en que éstas tradicionalmente venían jugando. Con el borrado minucioso de las fronteras de lo culto y lo popular, y acaso también rechazando visceralmente la relevancia concedida de antiguo a la singularidad, al unnicum, Duchamp ha dado un paso decisivo a favor de la simulación y el régimen de

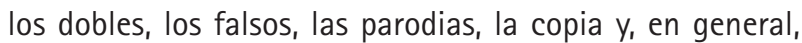
la perversión misma de la "imagen" (perversión que llega a su límite en las manipulaciones del discípulo Warhol, o de su coetáneo Salvador Dalí) ${ }^{37}$. Ello, además, ha visto reduplicado el efecto de su estatuto espectral con la aparición de la imagen incorpórea, virtual, fractal, hologramática ${ }^{38}$; también la pos-fotografía, objetos todos que apuntan a un tecno-sublime, a una sublimidad tecnológica ${ }^{39}$.

\section{GIRO VISUAL VS. GIRO LINGÜístICO}

Los efectos de esta ampliación sorpresiva se dejan sentir sobre todo desestabilizando la vieja pugna entre estudios de historia del arte vs. estudios de literatura -algo que se había mantenido latente en las viejas facultades europeas de Humanidades-, y obligan u obligarán muy pronto a una remodelación de las posiciones que sin duda deberán ir encaminadas a la creación, a su vez, de unos "estudios de la cultura del escrito" ${ }^{40}$, cuyo propio amanecer creo que ya puede comenzar a observarse en los manifiestos teóricos que desde hace veinte años producen estudiosos como Olson, Havelok o Chartier y Darnton, y que claramente han comenzado a desbordar el objeto textual inscrito canónicamente en la historia de la literatura, para dirigirse al escrito sin más determinaciones (como a la imagen sin más determinaciones se dirige ahora mismo la formación académica denominada, al menos en España a modo de tentativa: comunicación visual, en la que idealmente se engloban las imágenes artísticas, tanto como aquellas otras que no lo son, sucediendo en realidad que esa vieja distinción pierde toda su fuerza y eficacia, viniéndose a anular).

En suma, este inminente "giro visual"41, al desplazar la zona central de expresión de lo social desde el logos a la imago, supone un gran cambio de paradigma cultural y filosófico ${ }^{42}-y$, en realidad, una mutación epistemológica de primer orden-, pero sobre lo cual advertiremos en este punto uno de sus primeros efectos que pueden ser comprobados directamente con el valor paradigmático que la imagen comienza a cobrar, incluso en el interior del propio campo expositivo de otras disciplinas, como, entre todas, puede ser destacadamente la propia literatura, que pasa a ser así de disciplina colonizadora de mundos en la primera época de la modernidad, a resultar colonizada en la era posmoderna; dicho en otros términos: a constituirse en una suerte de parergon o suplemento para todo lo visual, inaugurando de este modo el declive de su estrella en la historia de los medios de representación. 
1 Para la revisión de este asunto en el Renacimiento italiano, véase el clásico Lee, 1982.

2 La dialéctica "pictura/poesis" ha podido ser invertida en nuestros días, en el sentido de encontrar, no sólo que la poesía pone ante los ojos la realidad del modo analógico, como lo hace la pintura, sino que de modo más profundo es el sistema de las artes visuales el que se dota de recursos descriptivos y retóricos extraídos de las artes del discurso, véase García Berrío y Hernández Fernández, 1988.

3 Cuestión que se hace muy evidente en el caso de la representación del rostro humano en la pintura, y que ha sido tratada por Gombrich, 1982.

4 Éste es el tinte mcluhaniano de nuestro momento histórico. Véase Mcluhan, 1968.

$5 Y$, sin embargo, la paradoja, como es bien sabido, reside en la común procedencia etimológica, tanto de los "signos" de la escritura, como de los "trazos" (de la pintura). Ambos en griego son graphe, graphein.

6 Asunto éste explorado en nuestra tradición inmediata por Lledó, 1992.

7 Imago mentis lograda en el texto mediante la operación retórica a la que se conoce como hypotiposis, una disposición del discurso textual u oral que "hace ver" y que configura la imagen mental de la cosa evocada, haciendo realidad la expresión de Simónides de Ceos: "La palabra es la imagen de las cosas".

8 Para la relación que se establece entre verdad y pintura, debe verse ahora Derrida, 2001.

9 Pues, en efecto, hay un inconsciente óptico que ha sido el objeto del

Recibido: 1 de diciembre de 2008 Aceptado: 1 de mayo de 2009 análisis de Krauss, 1997, tarea que la propia autora expresa como que "el deseo que anima El inconsciente óptico es empañar desde dentro de la visión moderna, nublando su enfoque cristalino, disipando sus sublimaciones y reubicando lo visual en una anatomía opaca impulsada por automatismos inconscientes" (87). Las relaciones entre la forma y lo inteligible han conocido un análisis de tipo historicista que permanece como un texto de referencia, el de Klein, 1980.

$10 \mathrm{Y}$, sin embargo, la literatura se esfuerza en suministrar las evidencias de su fuerza pragmática, como quedó inmortalizado en el "Canto V" del Infierno dantesco: alli Paolo y Francesca caen presas del amor al leer juntos un episodio del beso de Lanzarote y Ginebra: "Leímos un día por gusto como fue que el amor hirió a Lanzarote. Estábamos solos y sin sospecha. Nos miramos muchas veces durante aquella lectura, y nuestro rostro palideció; pero sólo fuimos vencidos por un pasaje. Cuando leímos que la deseada sonrisa fue besada por el amante, éste que ya nunca se apartará de mí, a su vez me besó temblando en la boca".

11 Mito del que ahora ofrece una revisión Stoichita, 2006.

12 Durand, 1981. Véase también, Sartre, 2005.

13 Sin embargo, lo cierto de la imagen es que ésta también se "lee". Sobre tal asunto véase: Manguel, 2002, y R. de la Flor, 1995.

$14 \mathrm{El}$ defensor más clarividente de esta imagen del mundo como texto conseguido a través de una operación de traslados abstractos es Olson, 1997. Sin embargo, y en lo que se refiere a la arqueología de esos mismos traslados, Baxandall, 1978, ha demostrado que en todo el Antiguo Régimen la realidad se trasladaba 
prioritariamente en la forma de imagen, tanto en la cartografía como en la retratística cuanto en otros objetos de producción simbólica basados en la primacía de la mirada, que se presenta desde luego, para toda una larga época, como el agente que constituye y canaliza la representación simbólica.

15 Habría sucedido que se habria abierto en la modernidad la "era de la imagen del mundo", el momento decisivo en que el mundo alcanza su representación en imágenes universales. Cuestión ésta avanzada por Heidegger, 1995, en su texto del año 38.

16 Algo de lo que vino a dar cuenta por vez primera en la historia del arte Abby Warburg, desarrollando en sus análisis los conceptos de pathosformel, engrama y dinamograma, con resonancias en la psicología profunda. Véase: Didi-Huberman, 2002.

17 Véase sobre tales imágenes dialécticas en la teoría benjaminiana, el libro de Buck-Morrs, 1995.

18 Como viene a demostrar un libro antes citado: el de Stoichita, 2006.

19 Si entendemos la escritura como prótesis de la memoria cognitiva, entonces es evidente que su crecimiento es nefasto para la memoria orgánica, que, en cambio, si se sacia y se fortifica en presencia de la imagen o de la cosa, al establecer un vínculo más fuerte y empático con ella. Ha desarrollado este punto de confrontación en lo que se refiere al patrimonio cultural Chuay, 2007.

20 Todas estas categorias tienen hoy a su filósofo en Virilio (1998), quien describe el proceso de constitución de la "imagen incorpórea" como un proceso de creciente "desrealización" del mundo. En suma, Virilio, retoma de nuevo el viejo asunto platónico de las imágenes en la caverna, y problematiza y hace aflorar la crisis específica de este nuestro tiempo, que sólo se deja percibir, precisamente, en este terreno de la visión humana y de la creación de imágenes; locus donde los límites de lo real y lo representado se hallan confundidos, contribuyendo efectivamente a un descrédito de la naturaleza física del mundo y a una espectralización de lo que él contiene.

21 Estoy, naturalmente, citando a Jean Braudrillard, 1993, y recordando subsidiariamente a Virilio, 1991.

22 Asunto sobre el cual aún permanece el magisterio de Benjamin, 1973.

23 He analizado (R. de la Flor, 2006) muy someramente estas condiciones que se producen en torno al hecho de la lecto-escritura, y que son en realidad protocolos melancólicos de negación del mundo, y he ampliado el campo de esas mismas observaciones en R. de la Flor, 2005. Sobre el tema general de una derrota final de las (Bellas) Letras, véase también $\mathrm{R}$. de la Flor, 2004.

24 Sobre estos problemas aquí evocados, véase Marin, 1978.

25 Pues, ciertamente, existe lo que podemos denominar una "dialéctica de la mirada", y un juego muy complejo en la observación, uno de cuyos primeros estudiosos es, de nuevo, Walter Benjamín. Véase este aspecto estudiado en la obra de Buck-Morss, 1996.

26 El término aparece ya aclimatado en obras como de la Mirzoeff, 2003.

27 La cuestión pide ser también leída en la forma de un cambio del paradigma epistémico entre dos épocas que resultan conexas. Si la primera fase de la modernidad capitalista decimonónica estuvo vinculada a una expansión sin precedentes de las culturas del escrito, las siguientes fases, hasta venir a dar en esta reciente, a la que conocemos como posmodernidad, se expresan a sí mismas en una implementación progresiva del régimen de lo visual, convirtiendo a este último registro en la "escena" verdadera de sus operaciones taumatúrgicas y de sus estrategias, que han podido ser consideradas desde el punto de vista del "hombre natural" como "estrategias fatales" (Baudrillard, 1984). Para esta dialéctica puede también verse el libro de Wellmer, 1993.

28 Proceso al cual, un fenomenólogo actual, Bruno Latour, ha podido bautizar como "iconoclash" (Latour, 2002).

29 Situación implosiva, la que resulta al cabo del desequilibrio contemporáneo de estas polaridades (palabra e imagen) que se habian mantenido como aliadas en un hoy lejano Antiguo Régimen, y que, junto a otra serie de causas, ha producido la crisis de las humanidades y de la institución universitaria que se encarga de gestionar tal saber. Para el caso peninsular ha dado cuenta de ello Thiebaut, 1999, y, de un modo que singularmente revisa el impacto del "giro visual", Brea, 2004. Véase también de este último, Brea, 2005.

30 El libro de los dos Filóstrato ha tenido una reciente e importante edición: Imágenes (Filóstrato, 1993). Véase, para el episodio de la galería de imágenes, el prólogo.

31 Para la formulación de este problema -que es el que se desarrolla en el seno de la estética vanguardista-, véase Monegal, 1998.

32 Citemos aquí de Guy Debord dos obras significativas por el espacio crítico que han generado, Debord, 1976 y Debord, 1990. También: Subirats, 2005. 
33 Para una rápida supervisión de esta "lógica cultural" enteramente nueva, veáse Jameson, 1995.

34 Desmontada a estos efectos por un Derrida, 2001.

35 Muerte entonces del arte cuyo más conspicuo profeta en nuestros días es Danto (2002).

36 Como puesta de largo de tal disciplina ocurrida en el contexto universitario americano, tal vez pueda fijarse el año 1996, con la encuesta publicada en la influyente revista October en su número 77 , donde un vasto conjunto de prestigiosos estudiosos de la imagen, críticos literarios y filósofos de la cultura contestaban un cuestionario muy completo, que ahora puede verse traducido en el número 1 de la revista Estudios visuales (Madrid), 2003, 82-125.

37 Sobre la imagen perversa, pero con otro sentido más estricto con relación a una determinada moral, véase el reciente libro de Gubern, 2005. Recordemos aquí también la aserción del teórico de la posmodernidad, Frederick Jameson, cuando escribe que "lo visual es básicamente pornográfico" (1990, 1).

38 Esta última "novedad" es trascendental, pues reintroduce en el estudio de la estética el valor heuristico que tiene una disciplina como el psicoanálisis, que ciertamente retorna entonces como una de las grandes formaciones del saber contemporáneo que no pueden sufrir un desplazamiento 0 , peor, un ocultamiento prolongado como al que parecía condenado en el campo tradicional de unos estudios de "historia del arte". La espectralización de la imagen omnipresente en los medios de comunicación, pone pues de actualidad ciertas apreciaciones pioneras de un Freud en su conjunto de ensayos reunidos bajo el título de Psicoanálisis del arte. Véase un cuestionamiento analítico de la relación entre estas dos esferas, en Scheneider, 1996, y, antes, en el libro de Versan, 1986.

39 De la que se ha ocupado Molinuevo, 1992.

40 Cultura del escrito que actúa bajo el presupuesto expresado por Christopher Word: "Yo argumentaria que los llamados textos estéticos no se diferencian en género de los textos en general. El texto estético es sólo un texto excepcionalmente ambiguo y cohibido" (Word, 2003, 124).

41 La fórmula está acreditada; en realidad se opone y sucede al denominado "giro lingüístico" o "giro semiótico", que expresa a su vez el triunfo de los modelos de textualidad, y cuya primera formulación se pude encontrar en la obra de Rortry, 1998, y, sobre todo, Rortry, 1999.

42 Reconozcamos aquí a quien fue el analista pionero en esta transformación fulgurante de la masa crítica de una cultura: Marshall Mac Luhan.

\section{BIBLIOGRAFÍA}

Arnheim, Rudolf (1969): Visual Thinking, Berkeley, University of California.

Baudrillard, Jean (1984): Las estrategias fatales, Barcelona, Anagrama.

Baudrillard, Jean (1993): Pantalla total, Barcelona, Anagrama.

Baxandall, Michael (1978): Pintura y vida cotidiana en el Renacimiento. Arte $y$ experiencia en el Quattrocento, Barcelona, Gustavo Gili.

Benjamín, Walter (1973): "La obra de arte en la era de su reproductibilidad técnica", en Discursos Interrumpidos I, Madrid, Taurus.

Brea, José Luis (2004): "La Universidad del conocimiento y las nuevas humani- dades", en Estudios visuales, n. 2 , 133-154.

Brea, José Luis (2005): Estudios visuales. La epistemología de la visualidad en la era de la globalización, Madrid, Akal.

Bryson, Norman (1991): Visión y pintura. La lógica de la mirada, Madrid, Alianza Forma.

Buck-Morrs, Susan (1995): Dialéctica de la mirada, Madrid, La Balsa de la Medusa.

Burke. Peter (2001): Visto y no visto. El uso de la imagen como documento histórico, Barcelona, Crítica.

Burucúa, José Emilio (2006): La imagen y la risa. Las pathosformel de lo cómico en el grabado europeo de la modernidad temparana, Mérida, Perférica.

Choay, François (2007): Alegoría del patrimonio, Barcelona, Gustavo Gili.

Danto, Arthur (2002): Después del fin del arte, Barcelona, Paidós.

Debord, Guy (1976): La sociedad del espectáculo, Barcelona, Castellote Editor.

Debord, Guy (1990): Comentarios sobre la sociedad del espectáculo, Barcelona, Editorial Anagrama.

Derrida, Jacques (1975): "La farmacia de Platón", en La diseminación, Madrid, Fundamentos.

Derrida, Jacques (1976): La diseminación, Madrid, Fundamentos.

Derrida, Jacques (2001): La verdad en pintura, Barcelona, Paidós.

Didi-Huberman, Georges (2002): L'Image survivante. Histoire de L'Art et temps des Fantômes selon Aby Warburg, Paris, Les Editions de Minuit

Didi-Huberman, Georges (2005): Ante el tiempo, Buenos Aires, Adriana Hidalgo.

Durand, Gilbert (1981): Las estructuras antropológicas de lo imaginario, Madrid, Taurus.

Eisenstein, E. (1979): The printing Press as an Agent of Change. Cambridge, Cambridge University Press. 
Fernández Magdalena, Diego (2005): El tiempo incinerado, LF ediciones, Béjar.

Filóstrato (1993): Imágenes, Luis Alberto de Cuenca (ed.), Madrid, Ediciones Siruela.

Foster, Hal (2001): El retorno a lo real. La vanguardia a fines de siglo, Madrid Akal.

Freedberg, David (1989): El poder de las imágenes, Madrid, Alianza.

García Berrío, Antonio y Hernández Fernández, Teresa (1988): Ut poesis pictura. Poética del arte visual, Barcelona, Tecnos.

Ginzburg, Carlo (2000): "Ecce, sobre las raices escriturales de la imagen de culto cristiana", en Ojazos de madera. Nueve reflexiones sobre la distancia, Barcelona, Península, 105-125.

Gombrich, Ernest (1982): "La máscara y la cara: la percepción del parecido fisiognómico en la vida y en el arte", en Gombrich et alt., Arte, percepción y realidad, Barcelona, Paidós, 168-192.

Gubern, Román (2005): La imagen perversa, Barcelona, Anagrama.

Heidegger, Martin (1995): "La época de la imagen del mundo", en Caminos de bosque, Madrid, Alianza, 63-91.

Hugo, Víctor (2006): "Esto matará aquello", en Nuestra Señora de París, Madrid, Gredos.

Ibáñez, Jordi (2004): La lupa de Beckett Antonio Machado.

Iving, William, H. jr. (1953): Prints and Visual Communication, Cambridge, M.A.

Jameson, Frederich (1990): Signaturas of the Visible, New York, Routledge.

Jameson, Frederich (1995): El posmodernismo o la lógica cultural del capitalismo avanzado, Barcelona, Paidós.

Jay, Martín (2003): "Regímenes escópicos de la modernidad", en Campos de fuerza entre la historia intelectual y la crítica cultural, Paidós, Buenos Aires.
Klein, Robert (1980): La forma y lo inteligible. Escritos sobre el Renacimiento y el arte moderno, Madrid, Taurus.

Krauss, Rosalind (1997): El inconsciente óptico, Barcelona, Técnos.

Latour, Bruno (1998): "Visualización y cognición: pensando con los ojos y con las manos", La Balsa de la Medusa, n. ${ }^{\circ} 45-$ 46, 77-129.

Latour, Bruno (2002): Iconoclash, Karslruhe, ZkM.

Lee, Rensselaer W. (1982): Ut pictura poesis, La teoría humanistica de la pintura, Madrid, Cátedra.

Lledó, Emilio (1992): El silencio de la escritura, Madrid, Centro de Estudios Constitucionales.

Marin, Louis (1978): Estudios semiológicos (La lectura de la imagen), Madrid, Alberto Corazón.

Manguel, Alberto (2002): Leer imágenes, Madrid, Alianza.

Mcluhan, Marshall (1968): La galaxia Gutemberg, Barcelona, Edicions 62.

Mirzoeff, Nicholas (2003): Una introducción a la cultura visual, Barcelona, Paidós.

Molinuevo, José Luis (1992): "El lado oscuro de lo sublime", en Gerard Vilar y Robert Rodríguez, En la cumbre del criticismo, Madrid, Temas, 152168.

Monegal, Antonio (1998): En los límites de la diferencia. Poesía e imagen en las vanguardias hispánicas, Madrid, Tecnos.

Moxey, Keith (2003): Teoría, práctica, persuasión, Barcelona, Ediciones del Serbal.

Olson, David R. (1997): El mundo sobre el papel. El impacto de la escritura y la lectura en la estructura del conocimiento, Barcelona, Gedisa.

R. de la Flor, Fernando (1995): Emblemas. Lecturas de la imagen simbólica, Madrid, Alianza.
R. de la Flor, Fernando (2004): Biblioclasmo. Una historia perversa de la literatura, Madrid, Renacimiento.

R. de la Flor, Fernando (2005): "Ergonomía de la lecto-escritura", Boletín de la Institución Libre de Enseñanza, n. ${ }^{\circ}$ 5960, 117-134.

R. de la Flor, Fernando (2006): "Protocolos afectivos e instrumentales a la praxis de la lecto-escritura", Sileno, n. ${ }^{0} 18$, 76-84.

Rortry, Richard (1998): El giro lingüistico, Barcelona, Paidós.

Rortry, Richard (1999): La filosofía y el espejo de la naturaleza, Barcelona, Paidós.

Sartre, Jean Paul (2005): "La función de la imagen en la vida psíquica", en Lo imaginario, Madrid, Losada, 147-187.

Scheneider, Laurie (1996): Arte y Psicoanálisis, Madrid, Cátedra.

Stoichita, Víctor (2006): Simulacro. El efecto Pygmalion. De Ovidio a Hitchcock Madrid, Siruela.

Venegas, Alejo (1540): Diferencias de los libros que hay en el Universo, Toledo, Juan Ayala.

Subirats, Eduardo (2005): en Las estrategias del espectáculo, Murcia, Cendeac.

Thiebaut, Carlos (1999): La responsabilidad ante el futuro (y el futuro de las humanidades), Valencia, Ediciones Episteme.

Versan, Leo (1986): The Freudian Body. Psicoanálisis and Art, New York, Columbia University Press.

Virilio, Paul (1989): La máquina de la visión, Barcelona, Anagrama.

Virilio, Paul (1991): L'écran du désert, París, Galilée.

Virilio, Paul (1998): Estética de la desaparición, Barcelona, Anagrama.

Wellmer, Albrecht (1993): Sobre la dialéctica de modernidad y postmodernidad, Madrid, La Balsa de la Medusa.

Word, Christopher (2003): "Cuestionario sobre cultura visual", en Estudios visuales, n. $1,124$. 